\title{
Genetic diagnostic features after failure of initial treatment with epidermal growth factor receptor (EGFR)-tyrosine kinase inhibitors among non-small-cell lung cancer patients harboring EGFR mutations
}

\author{
Yuichiro Takeda* D, Go Naka, Yoh Yamaguchi, Masao Hashimoto, Manabu Suzuki, Shinyu Izumi and
} Haruhito Sugiyama

\begin{abstract}
Background: Osimertinib, a third-generation epidermal growth factor receptor (EGFR)-tyrosine kinase inhibitor (TKI), can be used as second-line treatment for lung cancer patients harboring the T790M substitution. Although osimertinib is more effective than the first-generation EGFR-TKIs used for first-line treatment, its efficacy with respect to long-term patient survival remains unclear even upon the administration of a complete sequence of EGFR-TKI therapy. Moreover, limited information is available regarding genetic diagnostic approaches after the treatment of EGFR-TKI-naive patients. This study investigated the clinical characteristics of EGFR-mutated lung cancer patients harboring the T790M substitution resistant to EGFR-TKls, as well as the advantages of rebiopsy and liquid biopsy for these patients.

Methods: The medical records of patients screened for EGFR mutations were reviewed. Upon failure of naïve treatment with EGFR-TKIs, except for osimertinib, single-plexus cobas version 2 was repeatedly used to detect the T790M substitution in EGFR via tissue or liquid biopsy.

Results: From April 2016 through May 2019, 113 patients were found to harbor EGFR mutations. Sixty patients were treated with EGFR-TKIs, among whom 46 underwent tissue or liquid biopsy. Twenty-nine of these 46 (63\%) patients harbored the T790M substitution. In total, 141 rebiopsies were performed. The T790M substitution was detected in 24 of 43 tissue biopsies and 11 of 98 liquid biopsies. If patients displayed an EGFR exon 19 deletion, had a new lesion, and were administered gefitinib as first-line therapy, they were suspected to harbor the T790M substitution. Furthermore, the T790M substitution was detected through rebiopsy in patients with coexisting original mutations, brain metastases, tumor enlargement by $\geq 12 \mathrm{~mm}$, or metastases at minor sites.
\end{abstract}

Conclusion: Among patients with positive factors associated with the T790M mutation, repeated tissue or liquid biopsies are useful to maximize the detection rate of the T790M substitution. Furthermore, these biopsies need to be repeated numerous times in order to reduce "detection overlook" among such patients.

Keywords: T790M, Repeated biopsy, Single-plexus PCR, EGFR-TKI

\footnotetext{
*Correspondence: ytakeda@hosp.ncgm.go.jp

Department of Respiratory Medicine, National Center for Global Health and

Medicine, 1-21-1 Toyama, Shinjuku-ku, Tokyo 162-8655, Japan
}

\section{$\triangle B M C$}

(c) The Author(s). 2020 Open Access This article is licensed under a Creative Commons Attribution 4.0 International License, which permits use, sharing, adaptation, distribution and reproduction in any medium or format, as long as you give appropriate credit to the original author(s) and the source, provide a link to the Creative Commons licence, and indicate if changes were made. The images or other third party material in this article are included in the article's Creative Commons licence, unless indicated otherwise in a credit line to the material. If material is not included in the article's Creative Commons licence and your intended use is not permitted by statutory regulation or exceeds the permitted use, you will need to obtain permission directly from the copyright holder. To view a copy of this licence, visit http://creativecommons.org/licenses/by/4.0/ The Creative Commons Public Domain Dedication waiver (http://creativecommons.org/publicdomain/zero/1.0/) applies to the data made available in this article, unless otherwise stated in a credit line to the data. 


\section{Key message}

Three alternatives are currently available for the use of first- or second-generation epidermal growth factor receptor tyrosine kinase inhibitors (EGFR-TKIs) to treat EGFR-mutated lung cancer, such as single agents or combinatorial treatment with an anti-VEGF antibody or chemotherapy. After the failure of initial EGFR-TKI treatment, repeated biopsy is expected to maximize the detection of T790M substitutions, thus prompting osimertinib therapy. Patients with positive factors associated with the T790M mutation would benefit from biopsies repeated numerous times.

\section{Background}

Patients with metastatic non-small-cell lung cancer (NSCL C) harboring epidermal growth factor receptor (EGFR)-sensitizing mutations generally receive EGFR-tyrosine kinase inhibitors (TKIs) as the first-line treatment [1]. Five TKIs, including first- to third-generation TKIs, are available for EGFR-TKI therapy. Although most patients eventually become resistant to EGFR-TKIs, the EGFR p.Thr790Met point mutation (EGFR T790M) is detected in $30-50 \%$ of patients presenting with disease progression after receiving first- or second-generation TKIs [2, 3]. These patients can be treated with osimertinib, whereas other patients might be treated with cytotoxic chemotherapy. Although osimertinib is generally preferred as first-line therapy because of efficacy and tolerability [4], patients with disease progression upon osimertinib treatment have been administered only cytotoxic chemotherapy [5]. Recent studies have revealed numerous EGFR-TKI-based alternatives for firstline treatment. First-generation EGFR-TKIs have been used in combination with an anti-VEGF antibody or chemotherapy [6-8]. These clinical trials reported almost the same high efficacy as that of osimertinib, despite slightly increased toxicities. In these trials, the EGFR T790M substitution was also suspected in $\geq 50 \%$ of patients presenting with disease progression. Furthermore, second-generation EGFR-TKIs constitute first-line treatment alternatives for EGFR-mutated advanced NSCLC because no phase III clinical trial has compared the clinical efficacy of secondgeneration EGFR-TKIs and osimertinib. When NSCLC patients harboring EGFR mutations are administered EGFR-TKIs except for osimertinib as first-line treatment, approximately half of them qualify for osimertinib therapy. For second- or third-line treatment of patients with osimertinib to maximize the treatment duration for EGFRTKIs since April 2018 [9], it is essential to detect the T790M substitution maximally. Cobas ver. 2 can be used for companion diagnostic examination (CDx) [10]. Limited information is available on maximizing the detection of the T790M substitution using this type of CDx. Repeated rebiopsy is considered more effective in reducing "detection overlook" of the T790M mutation when rebiopsy is performed for patients with this mutation and disease progression with clinical features of the T790M substitution. The purpose of this study was to investigate the clinical characteristics of EGFR-mutated lung cancer patients harboring the T790M substitution that were resistant to EGFR-TKIs. Through this knowledge, we will be able to identify appropriate patients who require repeated tissue or liquid rebiopsy.

\section{Methods \\ Patients}

From April 2016 to May 2019, consecutive patients screened for $E G F R$ mutations were retrospectively reviewed at the National Center for Global Health and Medicine, Japan. The peptide nucleic acid-locked nucleic acid (PNALNA) PCR clamp method [11] was used to detect EGFR mutations, using tissue biopsy specimens during the initial diagnosis of non-small non-squamous-cell lung cancer. After lung cancer acquired clinical resistance to EGFRTKIs, the cobas ${ }^{\oplus}$ EGFR Mutation Test (Version 2; Roche Molecular Systems) [10] was repeatedly performed to detect T790M mutation status through tissue or liquid biopsy. Clinical resistance was defined as an increase in the monitoring of tumor markers, disease progression through radiological imaging, or clinical disease progression.

\section{Rebiopsy and genetic analysis}

All types of clinical rebiopsies were repeated when patients were suspected to be clinically resistant to EGFRTKIs. If patients were likely to provide tumor tissue through a clinical procedure (e.g., bronchoscopy or computed tomography (CT)-guided biopsy) at radiographic disease progression, they underwent tissue biopsy numerous times. Otherwise, liquid biopsy was performed. After each rebiopsy, $\operatorname{cobas}^{\circ}$ version 2 was used. When a new T790M substitution was detected, patients were administered osimertinib; if not, they were administered treatment other than osimertinib, such as cytotoxic chemotherapy or other molecular-targeted therapy. Tissue or liquid rebiopsies were repeated numerous times until the T790M substitution was detected. Cobas ${ }^{\ominus}$ version 2 is a single-plexus real-time PCR procedure to detect EGFR mutations, using unstained $5 \mu \mathrm{m}$ thick sections obtained from a formalinfixed paraffin-embed block and mounted on slides or whole-blood samples, as previously reported [10]. Mutations were analyzed at the central laboratory of LSI Medience Corporation (Tokyo, Japan).

\section{Data collection}

The following data were obtained from each patient's medical records: patient characteristics, including age, sex, smoking index, smoking status, comorbidities, and Eastern Cooperative Oncology Group performance status at diagnosis; oncological data, including histologic 
type, staging in accordance with the 8th edition of the TNM Classification of Malignant Tumors [12], tumor size of biopsy site, number of tumor lesions, metastatic organ, and EGFR mutation sites detected via the PNALNA PCR clamp method or cobas ${ }^{\oplus}$ version 2 ; treatment data, including surgical treatment, radiotherapy including radical or palliative radiation, and pharmacotherapy (gefitinib, erlotinib, afatinib, and osimertinib) for EGFRTKI-naïve lines; subsequent systemic therapies, including cytotoxic chemotherapy regimens, immunotherapy, or other molecular-targeted treatment; data on the best supportive care; and tumor markers for CEA $(\mathrm{ng} / \mathrm{mL})$. CT, positron-emission CT, and magnetic resolution imaging were performed within 1 month of each biopsy for corresponding biopsy specimens. Patients harboring the T790M substitution were defined under the category of "detection of at least one T790M using single-plexus PCR through any type of clinically available biopsy."

\section{Ethical considerations}

The study was conducted in accordance with the tenets of the Declaration of Helsinki. The study was approved by the certified review board of the National Center for Global Health and Medicine (NCGM-G-003361-00). In accordance with the Japanese Ethical Guidelines for Medical and Health Research Involving Human Subjects, we used the opt-out method. We informed the participants about this study and obtained informed consent from subjects by displaying the disclosure document in the hospital as per the approval date until January 31, 2020.

\section{Statistical analysis}

The primary outcome was the identification of clinical characteristics of EGFR-mutated lung cancer patients harboring the T790M substitution with acquired clinical resistance to EGFR-TKIs. Secondary outcomes included identifying factors inducing the T790M substitution through any type of rebiopsy among patients harboring the T790M substitution and factors through liquid rebiopsy. Fisher's exact test was performed to compare the proportion of subjects with dichotomous outcomes in both groups. We used some dichotomous variables from original continuous variables to be suitable for the logistic regression model. The optimal cutoff values of each continuous variable were set by receiver-operator characteristic (ROC) curves by SigmaPlot version 14 software (Systat Software, Inc., San Jose, CA, USA). At a $p$-value of $<0.05$, the optimal cutoff values of these continuous variables were set on the basis of a pre-test probability of 0.5 and a cost ratio of 1.0 .

Because logistic regression analysis can determine the strength of association between each factor and the outcome, this analysis was performed to assess the aforementioned three factors, as previously described [13]. To select a multivariate analysis model, we identified variables with a $p$-value of less than 0.15 based on univariate analysis. Spearman's rank test and clinically clarified dependent variables were used to exclude dependent variables from the aforementioned selected variables. A correlation coefficient $(\rho)$ of more than 0.3 as the absolute value based on Spearman's rank test indicated a significant association. Some models were constructed with only independent variables as candidates. ROC curves were used to select the best model among candidate models. In the final multivariate analysis using the simultaneous method, statistical significance was determined at $p<0.05$ through a two-sided test. All analyses were performed using SPSS Statistics software version 25 (IBM, Armonk, NY, USA) or Stata version 15.1 (StataCorp LLC, College Station, TX, USA).

\section{Results}

Patients

Among 405 consecutively examined patients, EGFR mutations were detected in 113 patients (Fig. 1). Five patients decided to undergo only the best supportive care, and 48 did not experience relapse after local therapy, including surgery, radiotherapy, or chemoradiotherapy. Sixty patients harbored activating EGFR mutations, and seven were administered osimertinib as TKI-naïve therapy. The remaining patients were treated with TKIs, except for osimertinib. The T790M substitution was detected in 29 of 46 (63\%) patients who underwent rebiopsy. Table 1 outlines the demographic characteristics of each group. Thirty-one patients presented with postoperative recurrence, and four patients presented with post-irradiation recurrence. During the overall study period, 33 patients received chemotherapy. During TKI-naïve treatment, 13 patients received gefitinib, 32 received erlotinib, and eight received afatinib.

\section{Rebiopsy outcomes}

To identify patients harboring the T790M substitution, all types of clinically available rebiopsies were performed numerous times (Table 2). Tissue biopsy was repeated a maximum of four times. During the initial tissue biopsy, the detection rate (DR) was $67.8 \%$, with a sensitivity of $80.8 \%$. After that, the DR was approximately $30 \%$, with a cumulative sensitivity (CS) of 77.4-79.3\%. In terms of liquid biopsy, the maximum frequency of rebiopsy was 10. During the initial liquid biopsy, the DR was $8.1 \%$, with a sensitivity of $13 \%$. During each liquid biopsy, the median DR was $8.6 \%$, ranging from 0 to $25 \%$, and the median cumulative sensitivity was $18.9 \%$, ranging from 16.7 to $20.6 \%$. In total, we performed 141 rebiopsies, including both tissue and liquid biopsies, from 46 patients (Table 3). Among these patients, 29 (63\%) harbored the T790M substitution. The T790M substitution was 


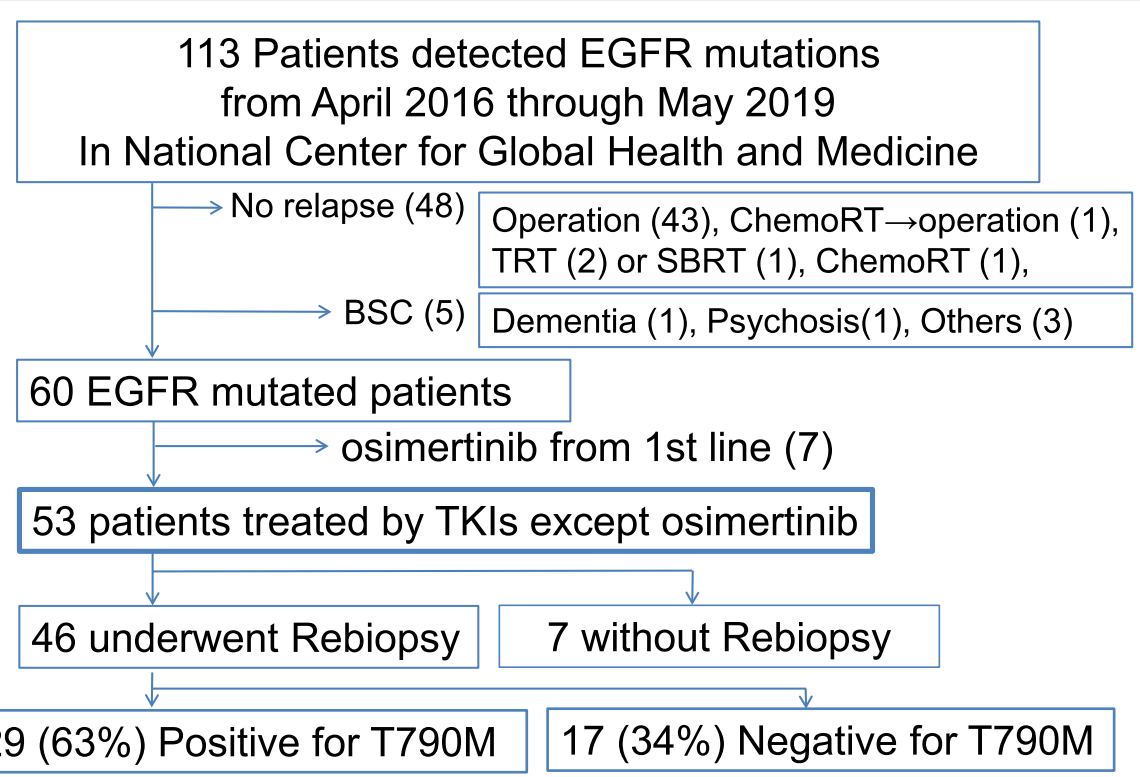

Fig. 1 Study cohort. The data are the number of patients, unless specified otherwise. The thick framed square indicates the full analysis set of this study

detected in 35 biopsies, with a CS of 39.3\%, including 24 tissue biopsies with $77.4 \%$ and 11 liquid biopsies with $19 \%$, respectively. Regarding the detection of the T790M substitution, significant differences between tissue and liquid biopsy were observed based on Fisher's exact test $(P<0.0001)$.

\section{Positive clinical factors in patients harboring the T790M substitution}

Our main purpose was to elucidate clinical features of positivity for the T790M substitution through clinically available mutational analysis. We considered the target patients with rebiopsy as 53 patients treated with TKIs except osimertinib, comprising the full analysis set (Fig. 1). Because logistic regression analysis can identify the strength of association between each clinical factor and the primary outcome, we analyzed 53 patients treated with EGFR-TKIs other than osimertinib. The results of logistic regression analyses are shown in Table 4 . Six variables had $p$-values $<0.15$ based on univariate analyses. Multivariate analysis indicated that significant clinical features associated with patients harboring the T790M substitution were as follows: exon 19 deletions in the original mutation, termination of TKIs owing to the detection of new lesions, and gefitinib in TKI-naïe treatment.

\section{Positive factors associated with the T790M substitution upon rebiopsy}

Because logistic regression analysis can find the degree of association between each clinical factor and one of the secondary outcomes, 89 rebiopsies were performed among patients harboring this mutation. Table 5 shows the background characteristics of patients harboring the T790M substitution upon rebiopsy. Logistic regression analyses revealed 16 variables with $p$-values $<0.15$ based on univariate analyses. We constructed four sets of multivariate models comprising variables that were not correlated with each other, as follows. Model 1 consisted of five variables, i.e., original mutation, brain metastases, enlargement of tumor size, mutation site at initial diagnosis, or minor site metastases, and the AUC was 0.916 . Model 2 consisted of original mutation, enlargement of tumor size, mutation site at initial diagnosis, minor site metastases, or new brain metastases, and the AUC was 0.911. Model 3 comprised variables, i.e., type of biopsy, brain metastases, mutation site at initial diagnosis, or minor site metastases, and the AUC was 0.881 . Model 4 comprised brain metastases, mutation site at initial diagnosis, enlargement of tumor size, or detection of new tumor lesion, with an AUC of 0.824 . The best model selected through ROC curve analysis is Model 1, as shown in Table 6. Multivariate analysis showed that the significant associations detected with the T790M substitution upon rebiopsy among patients harboring T790M were as follows: co-detection of the original mutation, co-occurring brain metastases, tumor enlargement of $\geq 12 \mathrm{~mm}$, or involvement of minor site metastases, which includes metastases of the skin, kidney, adrenal glands among other organs, as well as ascites and lymphangiosis carcinomatosa. 
Table 1 Patient background characteristics $(n=53)$

\begin{tabular}{|c|c|c|c|}
\hline \multirow[t]{4}{*}{ Variable } & \multicolumn{3}{|l|}{ Rebiopsy } \\
\hline & \multicolumn{2}{|l|}{$(+)$} & \multirow[t]{2}{*}{$(-)$} \\
\hline & \multicolumn{2}{|c|}{ T790M mutation } & \\
\hline & $\begin{array}{l}\text { Positive } \\
(n=29)\end{array}$ & $\begin{array}{l}\text { Negative } \\
(n=17)\end{array}$ & $\begin{array}{l}\text { Unknown } \\
(n=7)\end{array}$ \\
\hline \multicolumn{4}{|l|}{ Sex } \\
\hline Male & 11 & 3 & 3 \\
\hline Female & 18 & 14 & 4 \\
\hline Age (years) median (range) & $74(42-86)$ & $72(38-89)$ & $70(59-82)$ \\
\hline \multicolumn{4}{|l|}{ Histology } \\
\hline Adenocarcinoma & 27 & 17 & 7 \\
\hline others & 2 & 0 & 0 \\
\hline \multicolumn{4}{|l|}{ EGFR mutation at initial diagnosis } \\
\hline Exon 19 deletion & 21 & 6 & 1 \\
\hline L858R & 8 & 9 & 5 \\
\hline L861Q & 0 & 1 & 0 \\
\hline Exon 20 insertion & 0 & 1 & 0 \\
\hline Compound mutation & 0 & 0 & 1 \\
\hline \multicolumn{4}{|l|}{ Smoking status } \\
\hline Never & 18 & 13 & 3 \\
\hline Past & 8 & 1 & 2 \\
\hline Current & 3 & 3 & 2 \\
\hline \multicolumn{4}{|l|}{ ECOG performance status } \\
\hline 0 & 20 & 12 & 3 \\
\hline 1 & 8 & 5 & 2 \\
\hline 2 & 1 & 0 & 1 \\
\hline 3 & 0 & 0 & 1 \\
\hline \multicolumn{4}{|l|}{ Stage at initial diagnosis } \\
\hline$|A-||| C$ & 10 & 3 & 3 \\
\hline IVA - IVB & 19 & 14 & 4 \\
\hline \multicolumn{4}{|l|}{ Surgical treatment } \\
\hline No & 13 & 6 & 3 \\
\hline Yes & 16 & 11 & 4 \\
\hline \multicolumn{4}{|l|}{ Radical Radiotherapy } \\
\hline No & 27 & 16 & 6 \\
\hline Yes & 2 & 1 & 1 \\
\hline \multicolumn{4}{|l|}{ Chemotherapy during treatment } \\
\hline No & 8 & 6 & 6 \\
\hline Yes & 21 & 11 & 1 \\
\hline \multicolumn{4}{|l|}{ Reason for termination of TKIs } \\
\hline Ongoing & 1 & 5 & 3 \\
\hline Adverse events & 0 & 1 & 3 \\
\hline Tumor growth & 14 & 3 & 0 \\
\hline New lesions & 14 & 8 & 1 \\
\hline "CEA at progression" / "nadir CEA"; median (range) & $3.1(1.1-170)$ & $2.5(1.3-7.88)$ & $2.0(0.5-3.57)$ \\
\hline nadir CEA (ng/mL); median (range) & $3.0(0.8-36.9)$ & $2.2(1.0-78.9)$ & $45.6(1.4-198)$ \\
\hline
\end{tabular}


Table 1 Patient background characteristics $(n=53)$ (Continued)

\begin{tabular}{|c|c|c|c|}
\hline \multirow[t]{4}{*}{ Variable } & \multicolumn{3}{|c|}{ Rebiopsy } \\
\hline & \multicolumn{2}{|l|}{$(+)$} & \multirow[t]{2}{*}{$(-)$} \\
\hline & \multicolumn{2}{|c|}{ T790M mutation } & \\
\hline & $\begin{array}{l}\text { Positive } \\
(n=29)\end{array}$ & $\begin{array}{l}\text { Negative } \\
(n=17)\end{array}$ & $\begin{array}{l}\text { Unknown } \\
(n=7)\end{array}$ \\
\hline \multicolumn{4}{|c|}{ Medical Drugs at TKI naïve line } \\
\hline Gefitinib & 11 & 2 & 0 \\
\hline Erlotinib & 16 & 10 & 6 \\
\hline Afatinib & 2 & 5 & 1 \\
\hline
\end{tabular}

Abbreviations: ECOG Eastern Cooperative Oncology Group; TKI tyrosine kinase inhibitor; CEA carcinoembryonic antigen; "CEA at progression" / "nadir CEA" "Serum level of CEA at progression" divided by "Serum nadir level of CEA"; nadir CEA Serum nadir level of CEA

\section{Positive factors associated with the T790M substitution upon liquid biopsy}

Because logistic regression analysis can ascertain the degree of association between each clinical factor and the other secondary outcomes, 58 liquid biopsies were performed. The background characteristics of the group are shown in Table 7. The univariate logistic regression analyses obtained 11 variables. We also constructed four sets of multivariate models composed of variables that were not correlated with each other, as follows. Model 1 consisted of three variables, namely, mutation site at initial diagnosis, bone metastases, or detection of new tumor lesion, with an AUC of 0.936. Model 2 consisted of mutation site at initial diagnosis, enlargement of tumor size, or detection of new tumor lesion, and the
AUC was 0.879. Model 3 consisted of mutation site at initial diagnosis, brain metastases, or detection of new tumor lesion, and the AUC was 0.885 . Model 4 comprised mutation site at initial diagnosis, original mutation, or detection of new metastatic organ, and its AUC was 0.904. Among these models, the best model, Model 1, is shown in Table 8. Based on multivariate analysis, detecting the T790M substitution via liquid biopsy among patients harboring this mutation indicated the following: involvement of bone metastases or new tumor lesions $\geq 4$.

\section{Discussion}

Our primary purpose was to elucidate clinical features at the time of detection of T790M through clinically

Table 2 Number of biopsy and detection on T790M

\begin{tabular}{|c|c|c|c|c|c|c|c|c|c|c|c|}
\hline & $1 \mathrm{st}$ & 2nd & $3 r d$ & 4th & & & & & & & Total \\
\hline \multicolumn{12}{|c|}{ Tissue biopsy (Individual test) } \\
\hline T790M positive & 21 & 2 & 0 & 1 & & & & & & & 24 \\
\hline With original mutation & 26 & 5 & 3 & 3 & & & & & & & 37 \\
\hline Total & 31 & 6 & 3 & 3 & & & & & & & 43 \\
\hline \multicolumn{12}{|c|}{ Tissue biopsy (Cumulative test) } \\
\hline T790M positive & 21 & 23 & 23 & 24 & & & & & & & 24 \\
\hline Cumulative sensitivity & 0.81 & 0.79 & 0.77 & 0.77 & & & & & & & 0.77 \\
\hline \multirow[t]{2}{*}{ Total } & 31 & 37 & 40 & 43 & & & & & & & 43 \\
\hline & $1 \mathrm{st}$ & 2nd & 3 rd & 4th & 5th & 6th & 7th & 8th & 9th & 10th & Total \\
\hline \multicolumn{12}{|c|}{ Liquid biopsy (Individual test) } \\
\hline T790M positive & 3 & 4 & 1 & 0 & 0 & 1 & 1 & 1 & 0 & 0 & 11 \\
\hline With original mutation & 13 & 5 & 4 & 1 & 1 & 2 & 1 & 1 & 0 & 0 & 28 \\
\hline Total & 37 & 17 & 11 & 7 & 7 & 7 & 5 & 4 & 2 & 1 & 98 \\
\hline \multicolumn{12}{|c|}{ Liquid biopsy (Cumulative test) } \\
\hline T790M positive & 3 & 7 & 8 & 8 & 8 & 9 & 10 & 11 & 11 & 11 & 11 \\
\hline Cumulative sensitivity & 0.13 & 0.21 & 0.2 & 0.18 & 0.17 & 0.17 & 0.18 & 0.19 & 0.19 & 0.19 & 0.19 \\
\hline Total & 37 & 54 & 65 & 72 & 79 & 86 & 91 & 95 & 97 & 98 & 98 \\
\hline
\end{tabular}


Table 3 Rebiopsy outcomes

\begin{tabular}{|c|c|c|c|}
\hline \multirow[t]{2}{*}{ Variable } & \multicolumn{2}{|l|}{ T790M mutation } & \multirow[b]{2}{*}{ Total patients $(n=46)$} \\
\hline & Positive patients $(n=29)$ & Negative patients $(n=17)$ & \\
\hline Tissue biopsy (included cytology) count & 31 & 12 & 43 \\
\hline T790M positive count & $24(77.4)$ & - & $24(55.8)$ \\
\hline With Original mutation & 22 & - & 22 \\
\hline Without Original mutation & 2 & - & 2 \\
\hline T790M negative count & $7(22.6)$ & 12 & $19(44.2)$ \\
\hline With Original mutation & 5 & 10 & 15 \\
\hline Without Original mutation & 2 & 2 & 4 \\
\hline Liquid biopsy count & 58 & 40 & 98 \\
\hline T790M positive count & $11(19.0)$ & - & $11(11.2)$ \\
\hline With Original mutation & 10 & - & 10 \\
\hline Without Original mutation & 1 & - & 1 \\
\hline T790M negative count & $47(81.0)$ & 40 & $87(88.8)$ \\
\hline With Original mutation & 9 & 11 & 20 \\
\hline Without Original mutation & 38 & 29 & 67 \\
\hline Total rebiopsy count & 89 & 52 & 141 \\
\hline
\end{tabular}

Data are number of patients (\%) unless specified otherwise

available mutational analysis. If we could identify these clinical features, we could perform tissue or liquid rebiopsy with more appropriate timing and reduce the frequency of tissue or liquid biopsy while maintaining the maximum DR of T790M. Accordingly, this study investigated the characteristics of EGFR-mutated lung cancer patients harboring the T790M substitution that was resistant to EGFR-TKIs in order to identify patients with positive features who require tissue and liquid rebiopsy. In this study, repeated biopsy revealed that $63 \%$ of EGFR-mutated NSCLC patients harbored the T790M substitution after acquiring clinical resistance to EGFRTKIs. Tissue biopsy was superior to liquid biopsy in detecting T790M $(p<0.0001)$. Because liquid biopsy is a

Table 4 Logistic regression analysis to identify patients harboring the T790M substitution among those with EGFR-mutated lung cancer $(n=53)$

\begin{tabular}{|c|c|c|c|c|c|c|}
\hline \multirow[t]{2}{*}{ Variables } & \multicolumn{3}{|c|}{ Univariate Analyses } & \multicolumn{3}{|c|}{ Multivariate Analysis } \\
\hline & OR & $95 \% \mathrm{Cl}$ & P-value & OR & $95 \% \mathrm{Cl}$ & P-value \\
\hline Mutation site at initial diagnosis; Exon 19 Deletion vs. L858R & 0.17 & $0.05-0.51$ & 0.002 & 0.04 & $0.004-0.34$ & 0.003 \\
\hline Reason for termination of TKIs; & 2.26 & $1.25-4.11$ & 0.007 & 3.65 & $1.39-9.59$ & 0.008 \\
\hline Ongoing & \multicolumn{3}{|c|}{ Reference } & \multicolumn{3}{|c|}{ Reference } \\
\hline AES & 1 & - & - & 1 & - & - \\
\hline Tumor growth & 37.3 & $3.30-421.6$ & 0.003 & 33.8 & $1.60-713.3$ & 0.024 \\
\hline New lesions & 12.4 & $1.32-117.0$ & 0.027 & 44.9 & $2.13-950.9$ & 0.014 \\
\hline Medical Drugs at TKI-naïve line & 0.24 & $0.08-0.72$ & 0.01 & 0.09 & $0.01-0.62$ & 0.014 \\
\hline Gefitinib & \multicolumn{3}{|c|}{ Reference } & \multicolumn{3}{|c|}{ Reference } \\
\hline Erlotinib & 0.18 & $0.035-0.95$ & 0.044 & 0.49 & $0.02-0.99$ & 0.049 \\
\hline Afatinib & 0.06 & $0.007-0.55$ & 0.012 & 0.01 & $0.0002-0.53$ & 0.02 \\
\hline Chemotherapy; absent vs. present & 2.63 & $0.84-8.22$ & 0.09 & $\mathrm{NI}$ & & \\
\hline "Serum level of CEA at progression" divided by "Serum nadir level of CEA" & 1.16 & $0.97-1.39$ & 0.11 & 1.22 & $0.77-1.93$ & 0.4 \\
\hline Serum nadir level of CEA (ng/mL) & 0.97 & $0.95-1.01$ & 0.14 & $\mathrm{NI}$ & & \\
\hline
\end{tabular}

Abbreviations: OR Odds ratio; $C I$ confidence interval; $T K I$ tyrosine kinase inhibitor; $A E s$ adverse effects; CEA carcinoembryonic antigen; Variables with a p-value < 0.15 on univariate analysis were entered into multivariate logistical analysis by a simultaneous method. $\mathrm{NI}$, not included in the best multivariate logistic regression model 
Table 5 Background characteristics on patients harboring the T790M substitution upon rebiopsy $(n=89)$

\begin{tabular}{|c|c|c|c|}
\hline \multirow[t]{2}{*}{ Variable } & \multicolumn{2}{|c|}{ T790M mutation } & \multirow[b]{2}{*}{ Total } \\
\hline & $\begin{array}{l}\text { Positive } \\
(n=35)\end{array}$ & $\begin{array}{l}\text { Negative } \\
(n=54)\end{array}$ & \\
\hline \multicolumn{4}{|l|}{ Original mutation } \\
\hline Absent & 3 & 40 & 43 \\
\hline Present & 32 & 14 & 46 \\
\hline \multicolumn{4}{|l|}{ Type of Biopsy; } \\
\hline Liquid & 11 & 47 & 58 \\
\hline Tissue & 24 & 7 & 31 \\
\hline \multicolumn{4}{|c|}{ Detection of New tumor lesion; } \\
\hline$<4$ & 11 & 39 & 50 \\
\hline $4 \leq$ & 24 & 15 & 39 \\
\hline \multicolumn{4}{|c|}{ Number of Tissue biopsy } \\
\hline Median (Range) & $1(0-4)$ & $0(0-3)$ & $0(0-4)$ \\
\hline \multicolumn{4}{|c|}{ Detection of New metastatic organ, $n=88$} \\
\hline 0 & 12 & 39 & 51 \\
\hline 1 & 12 & 10 & 22 \\
\hline 2 & 4 & 4 & 8 \\
\hline 3 & 3 & 1 & 4 \\
\hline 4 & 3 & 0 & 3 \\
\hline \multicolumn{4}{|c|}{ Number of tumor lesion } \\
\hline$<6$ & 6 & 29 & 35 \\
\hline $6 \leq$ & 29 & 25 & 54 \\
\hline \multicolumn{4}{|c|}{ Brain metastases, $n=88$} \\
\hline Absent & 16 & 43 & 59 \\
\hline Present & 18 & 11 & 29 \\
\hline \multicolumn{4}{|c|}{ Bone metastases, $n=88$} \\
\hline Absent & 26 & 42 & 68 \\
\hline Present & 8 & 12 & 20 \\
\hline \multicolumn{4}{|c|}{ Number of Liquid biopsy } \\
\hline Median (Range) & $0(0-8)$ & $2(0-9)$ & $1(0-9)$ \\
\hline \multicolumn{4}{|c|}{ Enlargement of Tumor size } \\
\hline$<12 \mathrm{~mm}$ & 15 & 39 & 54 \\
\hline $12 \mathrm{~mm} \leq$ & 20 & 15 & 35 \\
\hline \multicolumn{4}{|c|}{ New brain metastases, $\mathrm{n}=88$} \\
\hline Absent & 25 & 50 & 75 \\
\hline Present & 9 & 4 & 13 \\
\hline \multicolumn{4}{|c|}{ Mutation site at initial diagnosis } \\
\hline Exon19 Deletion & 24 & 47 & 71 \\
\hline L858R & 11 & 7 & 18 \\
\hline \multicolumn{4}{|c|}{ Minor site metastases, $n=88$} \\
\hline Absent & 27 & 51 & 78 \\
\hline Present & 7 & 3 & 10 \\
\hline \multicolumn{4}{|c|}{ New hepatic metastases, $n=88$} \\
\hline Absent & 28 & 51 & 79 \\
\hline
\end{tabular}


Table 5 Background characteristics on patients harboring the T790M substitution upon rebiopsy $(n=89)$ (Continued)

\begin{tabular}{|c|c|c|c|}
\hline \multirow[t]{2}{*}{ Variable } & \multicolumn{2}{|c|}{ T790M mutation } & \multirow[b]{2}{*}{ Total } \\
\hline & $\begin{array}{l}\text { Positive } \\
(n=35)\end{array}$ & $\begin{array}{l}\text { Negative } \\
(n=54)\end{array}$ & \\
\hline Present & 6 & 3 & 9 \\
\hline \multicolumn{4}{|c|}{ New minor site metastases, $\mathrm{n}=88$} \\
\hline Absent & 29 & 52 & 81 \\
\hline Present & 5 & 2 & 7 \\
\hline \multicolumn{4}{|c|}{ Hepatic metastases, $\mathrm{n}=88$} \\
\hline Absent & 27 & 49 & 76 \\
\hline Present & 7 & 5 & 12 \\
\hline
\end{tabular}

Abbreviations: n; number, minor site metastases; metastases of skin, kidney, ascites, lymphangiosis carcinomatosa, adrenal organ or others,

noninvasive biopsy modality for molecular-targeted analysis, including EGFR mutational status, it is easily reproducible using a plasma sample. The present results indicate that liquid biopsy is associated with more falsenegative results in clinical practice at levels of detection of approximately $0.1-2 \%[14,15]$. When liquid biopsy through this test yields negative findings for the T790M substitution, it is essential to perform a tissue biopsy. Because of its high sensitivity and high DR, tissue biopsy should receive first priority.

When deciding to perform or repeat biopsy, the three relevant factors in Table 4 should be considered. We estimated the probability of detecting the T790M mutation considering the number of rebiopsies among patients with such clinical characteristics.

The timing and site are essential factors to consider for each rebiopsy (Table 6). Based on the timing of the biopsy, patients had brain metastases and minor metastases, and their tumor lesions were enlarged by $>12 \mathrm{~mm}$. The enlarged tumor site would be better for tissue biopsy. When patients had bone metastases and harbored more than four new tumor lesions compared with previous tumor lesions, liquid biopsy was considered to detect the T790M substitution (Table 8).

This study has several limitations. Despite including consecutive patients herein, our study had a single-

Table 6 Logistic regression analysis to identify patients harboring the T790M substitution upon rebiopsy $(n=89)$

\begin{tabular}{|c|c|c|c|c|c|c|}
\hline \multirow[t]{2}{*}{ Variables } & \multicolumn{3}{|c|}{ Univariate Analyses } & \multicolumn{3}{|c|}{ Multivariate Analysis } \\
\hline & $\overline{\mathrm{OR}}$ & $95 \% \mathrm{Cl}$ & $P$-value & $\overline{\mathrm{OR}}$ & $95 \% \mathrm{Cl}$ & $P$-value \\
\hline Original mutation; absent vs. present & 30.5 & $8.05-115.3$ & $<0.001$ & 41.5 & $6.53-264.3$ & $<0.001$ \\
\hline Type of Biopsy; Liquid vs. Tissue & 14.6 & $5.04-42.6$ & $<0.001$ & $\mathrm{NI}$ & & \\
\hline Detection of New tumor lesion; $<4$ vs $4 \leq$ & 5.67 & $2.24-14.4$ & $<0.001$ & $\mathrm{NI}$ & & \\
\hline Number of Tissue biopsy & 5.72 & $2.30-14.2$ & $<0.001$ & $\mathrm{NI}$ & & \\
\hline Detection of New metastatic organ; $0 \rightarrow 4$ & 2.35 & $1.39-3.97$ & 0.001 & $\mathrm{NI}$ & & \\
\hline Number of tumor lesion; $<6$ vs $6 \leq$ & 5.61 & $2.0-15.7$ & 0.001 & $\mathrm{NI}$ & & \\
\hline Brain metastases; absent vs. present & 4.40 & $1.71-11.3$ & 0.002 & 27.8 & $3.13-247.8$ & 0.003 \\
\hline Bone metastases; absent vs. present & 3.94 & $1.55-9.98$ & 0.004 & $\mathrm{NI}$ & & \\
\hline Number of Liquid biopsy & 0.69 & $0.52-0.90$ & 0.006 & $\mathrm{Nl}$ & & \\
\hline Enlargement of Tumor size; $<12 \mathrm{~mm}$ vs $12 \mathrm{~mm} \leq$ & 3.47 & $1.42-8.49$ & 0.007 & 24.5 & $2.65-226.7$ & 0.005 \\
\hline New brain metastases; absent vs. present & 4.5 & $1.26-16.1$ & 0.02 & $\mathrm{NI}$ & & \\
\hline Mutation site at initial diagnosis; Exon19 Deletion vs. L858R & 3.08 & $1.06-8.95$ & 0.04 & 3.90 & $0.63-24.3$ & 0.145 \\
\hline Minor site metastases; absent vs. present & 4.20 & $1.07-16.5$ & 0.04 & 21.3 & $1.40-325.6$ & 0.03 \\
\hline New hepatic metastases; absent vs. present & 3.64 & $0.85-15.7$ & 0.08 & $\mathrm{NI}$ & & \\
\hline New minor site metastases; absent vs. present & 4.48 & $0.82-24.6$ & 0.08 & $\mathrm{NI}$ & & \\
\hline Hepatic metastases; absent vs. present & 2.54 & $0.99-1.09$ & 0.141 & $\mathrm{NI}$ & & \\
\hline
\end{tabular}

Abbreviations: OR Odds ratio; $C$ confidence interval; Variables with a $p$-value $<0.15$ on univariate analysis were entered into multivariate logistical analysis by a simultaneous method. $\mathrm{NI}$ not included in the best multivariate logistic regression model 
Table 7 Background characteristics on patients harboring the T790M substitution through liquid biopsy $(n=58)$

\begin{tabular}{|c|c|c|c|}
\hline \multirow[t]{2}{*}{ Variable } & \multicolumn{2}{|c|}{ T790M mutation } & \multirow[b]{2}{*}{ Total } \\
\hline & $\begin{array}{l}\text { Positive } \\
(n=11)\end{array}$ & $\begin{array}{l}\text { Negative } \\
(n=47)\end{array}$ & \\
\hline \multicolumn{4}{|l|}{ Original mutation } \\
\hline Absent & 1 & 38 & 39 \\
\hline Present & 10 & 9 & 19 \\
\hline \multicolumn{4}{|l|}{ Bone metastases } \\
\hline Absent & 1 & 39 & 40 \\
\hline Present & 10 & 8 & 18 \\
\hline \multicolumn{4}{|c|}{ Enlargement of Tumor size } \\
\hline$<12 \mathrm{~mm}$ & 7 & 7 & 14 \\
\hline $12 \mathrm{~mm} \leq$ & 4 & 40 & 44 \\
\hline \multicolumn{4}{|l|}{ Brain metastases } \\
\hline Absent & 4 & 38 & 42 \\
\hline Present & 7 & 9 & 16 \\
\hline \multicolumn{4}{|c|}{ Detection of New tumor lesion } \\
\hline$<4$ & 4 & 38 & 42 \\
\hline $4 \leq$ & 7 & 9 & 16 \\
\hline \multicolumn{4}{|c|}{ Detection of New metastatic organ } \\
\hline 0 & 6 & 36 & 42 \\
\hline 1 & 2 & 7 & 9 \\
\hline 2 & 0 & 3 & 3 \\
\hline 3 & 1 & 1 & 2 \\
\hline 4 & 2 & 0 & 2 \\
\hline \multicolumn{4}{|c|}{ New minor site metastases } \\
\hline Absent & 8 & 45 & 53 \\
\hline Present & 3 & 2 & 5 \\
\hline \multicolumn{4}{|l|}{ Hepatic metastases } \\
\hline Absent & 8 & 44 & 52 \\
\hline Present & 3 & 3 & 6 \\
\hline \multicolumn{4}{|l|}{ Minor site metastases } \\
\hline Absent & 8 & 44 & 52 \\
\hline Present & 3 & 3 & 6 \\
\hline \multicolumn{4}{|c|}{ Mutation site at initial diagnosis } \\
\hline Exon19 Deletion & 4 & 41 & 45 \\
\hline L858R & 7 & 6 & 13 \\
\hline \multicolumn{4}{|c|}{ New hepatic metastases } \\
\hline Absent & 9 & 45 & 54 \\
\hline Present & 2 & 2 & 4 \\
\hline
\end{tabular}

Abbreviations: $n$ number, minor site metastases; metastases of skin, kidney, ascites, lymphangiosis carcinomatosa, adrenal organ or others,

center, real-world, retrospective design. Although 405 consecutive patients were screened for the EGFR mutation for 3 years, they were detected in only $28 \%$ of patients (Fig. 1). Furthermore, our patient cohort comprised only 53 patients and was thus a small cohort for obtaining clinical data. Owing to remarkable progress in NSCLC treatment, we consider only minor benefits would be obtained even if we spend longer time to obtain the clinical data. In clinical practice, information from real-world data would be useful for repeated molecular analyses. 
Table 8 Logistic regression analysis to identify patients harboring the T790M substitution through liquid biopsy $(n=58)$

\begin{tabular}{|c|c|c|c|c|c|c|}
\hline \multirow[t]{2}{*}{ Variables } & \multicolumn{3}{|c|}{ Univariate Analyses } & \multicolumn{3}{|c|}{ Multivariate Analysis } \\
\hline & OR & $95 \% \mathrm{Cl}$ & P-value & OR & $95 \% \mathrm{Cl}$ & $P$-value \\
\hline Original mutation; absent vs. present & 42.2 & $4.77-373.6$ & 0.001 & $\mathrm{NI}$ & & \\
\hline Bone metastases; absent vs. present & 48.8 & $5.45-436.4$ & 0.001 & 77.9 & $5.32-1140$ & 0.001 \\
\hline Enlargement of Tumor size; < $12 \mathrm{~mm}$ vs $12 \mathrm{~mm} \leq$ & 0.10 & $0.02-0.43$ & 0.002 & $\mathrm{Nl}$ & & \\
\hline Brain metastases; absent vs. present & 7.39 & $1.77-30.8$ & 0.006 & $\mathrm{Nl}$ & & \\
\hline Detection of New tumor lesion; $<4$ vs $4 \leq$ & 7.39 & $1.77-30.8$ & 0.006 & 14.5 & $1.38-151.2$ & 0.026 \\
\hline Detection of New metastatic organ; $0 \rightarrow 4$ & 1.98 & $1.09-3.59$ & 0.024 & $\mathrm{NI}$ & & \\
\hline New minor site metastases; absent vs. present & 8.44 & $1.21-58.8$ & 0.031 & $\mathrm{NI}$ & & \\
\hline Hepatic metastases; absent vs. present & 5.50 & $0.94-32.2$ & 0.059 & $\mathrm{NI}$ & & \\
\hline Minor site metastases; absent vs. present & 5.50 & $0.94-32.2$ & 0.059 & $\mathrm{Nl}$ & & \\
\hline Mutation site at initial diagnosis; Exon19 Deletion vs. L858R & 3.91 & $0.87-17.5$ & 0.075 & 1.15 & $0.13-10.1$ & 0.897 \\
\hline New hepatic metastases; absent vs. present & 5.00 & $0.62-40.3$ & 0.131 & $\mathrm{NI}$ & & \\
\hline
\end{tabular}

Abbreviations: OR Odds ratio; $C l$ confidence interval; Variables with a $p$-value $<0.15$ on univariate analysis were entered into multivariate logistical analysis by a simultaneous method. $N /$ not included in the best multivariate logistic regression model

Nonetheless, this study also has some strengths. Upon testing for EGFR-mutant tumors by single-plexus PCR, tissue biopsy still received first priority. Because individuals with drivers receiving a matched targeted agent lived longer [16], we consider that patients with clinical characteristics similar to those harboring the T790M mutation should undergo repeated tissue or liquid rebiopsies until this mutation is detected. Furthermore, these results will help select the type or timing of biopsy.

\section{Conclusion}

For patients with positive factors associated with the T790M substitution, this study proposes that repeated biopsy helps to maximize the DR of the T790M mutation and that rebiopsy should be repeated numerous times until this mutation is detected.

\section{Abbreviations}

NSCLC: Non-small cell lung cancer; EGFR: Epidermal growth factor receptor; TKI: Tyrosine kinase inhibitor; T790M: EGFR p.Thr790Met point mutation; VEGF: Vascular endothelial growth factor; CDx: Companion diagnostic examination; PCR: Polymerase chain reaction; PNA-LNA PCR clamp method: Peptide nucleic acid - locked nucleic acid PCR clamp method; PS: Performance status; CT: Computer tomography; ROC: Receiver-operator characteristics; DR: Detection rate; CS: Cumulative sensitivity

\section{Acknowledgements}

The authors gratefully thank all the patients in this study and the staff at our department for their work and support of this study. We would like to thank Editage (www.editage.com) for English language editing.

\section{Authors' contributions}

Conceptualization and design: YT. Collected all clinical and genetic information: YT, GO, YY, MH, MS, SI. Data analysis and interpretation: GO, YT. Writing an original draft: YT. Reviewed, methodology and edited this manuscript: GO, SI, HS. Final approval of the manuscript: all authors.

\section{Funding}

Not applicable.

\section{Availability of data and materials}

All data generated or analyzed during this study are included in this published article. The datasets used and/or analyzed during the current study are available by contacting the corresponding author on a reasonable request.

\section{Ethics approval and consent to participate}

The study was conducted in accordance with the tenets of the Declaration of Helsinki. The study was approved by the certified review board of the National Center for Global Health and Medicine (NCGM-G-003361-00). Given that this study was a retrospective study, informed consent was waived. However, we did guarantee the opportunity by opt-out. We described the disclosure document about this study and obtained informed consent from subjects by displaying it in the hospital as per the approval date until 31st January 2020 approved by the certified review board.

\section{Consent for publication}

Not applicable.

\section{Competing interests}

YT has received grants from Boehringer Ingelheim, Chugai Pharmaceutical, outside of this study. The remaining authors declared no competing interests for this work.

Received: 25 March 2020 Accepted: 16 September 2020

Published online: 02 October 2020

\section{References}

1. Hanna N, Johnson D, Temin S, Baker S Jr, Brahmer J, Ellis PM, et al. Systemic therapy for stage IV non-small cell lung cancer: American Society of Clinical Oncology clinical practice guideline update. J Clin Oncol. 2017;35:3484-515.

2. Yu HA, Arcila ME, Rekhtman N, Sima CS, Zakowski MF, Pao W, et al. Analysis of tumor specimens at the time of acquired resistance to EGFR-TKI therapy in 155 patients with EGFR-mutant lung cancers. Clin Cancer Res. 2013;19: 2240-7.

3. Kawamura T, Kenmotsu H, Taira T, Omori S, Nakashima K, Wakuda K, et al. Rebiopsy for patients with non-small-cell lung cancer after epidermal growth factor receptor-tyrosine kinase inhibitor failure. Cancer Sci. 2016;107: $1001-5$

4. Ramalingam SS, Vansteenkiste J, Planchard D, Cho BC, Gray JE, Ohe Y, et al. Overall survival with Osimertinib in untreated, EGFR-mutated advanced NSCLC. N Engl J Med. 2020;382:41-50.

5. NCCN clinical practice guidelines in oncology for non-small cell lung cancer; version 2.2020, Dec 23th 2019.

6. Saito H, Fukuhara T, Furuya N, Watanabe K, Sugawara S, Iwasawa S, et al. Erlotinib plus bevacizumab versus erlotinib alone in patients with EGFR- 
positive advanced non-squamous non-small-cell lung cancer (NEJ026): interim analysis of an open-label, randomised, multicentre, phase 3 trial. Lancet Oncol. 2019;20:625-35.

7. Nakagawa K, Garon EB, Seto T, Nishio M, Ponce Aix S, Paz-Ares L, et al. Ramucirumab plus erlotinib in patients with untreated, EGFR-mutated advanced non-small-cell lung cancer (RELAY): a randomised, double-blind, placebo-controlled, phase 3 trial. Lancet Oncol. 2019;20:1655-69.

8. Hosomi Y, Morita S, Sugawara S, Kato T, Fukuhara T, Gemma A, et al. Gefitinib alone versus gefitinib plus chemotherapy for non-small-cell lung cancer with mutated epidermal growth factor receptor: NEJ009 study. J Clin Oncol. 2020;38:115-23.

9. Mok TS, Wu Y-L, Ahn M-J, Garassino MC, Kim HR, Ramalingam SS, et al. Osimertinib or platinum-pemetrexed in EGFR T790M-positive lung cancer. N Engl J Med. 2017;376:629-40.

10. John T, Akamatsu H, Delmonte A, Su WC, Lee JS, Chang GC, et al. EGFR mutation analysis for prospective patient selection in AURA3 phase III trial of osimertinib versus platinum-pemetrexed in patients with EGFR T790Mpositive advanced non-small-cell lung cancer. Lung Cancer. 2018;126:133-8.

11. Ito K, Suzuki Y, Saiki H, Sakaguchi T, Hayashi K, Nishii Y, et al. Utility of liquid biopsy by improved PNA-LNA PCR clamp method for detecting EGFR mutation at initial diagnosis of non-small-cell lung cancer: observational study of 190 consecutive cases in clinical practice. Clin Lung Cancer. 2018;19:181-90.

12. Goldstraw P, Chansky K, Crowley J, Rami-Porta R, Asamura H, Eberhardt WE, et al. The IASLC lung cancer staging project: proposals for revision of the TNM stage groupings in the forthcoming (eighth) edition of the TNM classification for lung cancer. J Thorac Oncol. 2016:11:39-51.

13. Kitazawa H, Takeda Y, Naka G, Sugiyama H. Decision-making factors for best supportive care alone and prognostic factors after best supportive care in non-small cell lung cancer patients. Sci Rep. 2019;9:19872.

14. Buder A, Setinek U, Hochmair MJ, Schwab S, Kirchbacher K, Keck A, et al. EGFR mutations in cell-free plasma DNA from patients with advanced lung adenocarcinoma: improved detection by droplet digital PCR. Target Oncol. 2019 Apr;14(2):197-203.

15. Bennett CW, Berchem G, Kim YJ, El-Khoury V. Cell-free DNA and nextgeneration sequencing in the service of personalized medicine for lung cancer. Oncotarget. 2016;7(43):71013-35.

16. Kris MG, Johnson BE, Berry LD, Kwiatkowski DJ, lafrate AJ, Wistuba II, et al. Using multiplexed assays of oncogenic drivers in lung cancers to select targeted drugs. JAMA. 2014;311:1998-2006.

\section{Publisher's Note}

Springer Nature remains neutral with regard to jurisdictional claims in published maps and institutional affiliations.

Ready to submit your research? Choose BMC and benefit from:

- fast, convenient online submission

- thorough peer review by experienced researchers in your field

- rapid publication on acceptance

- support for research data, including large and complex data types

- gold Open Access which fosters wider collaboration and increased citations

- maximum visibility for your research: over $100 \mathrm{M}$ website views per year

At $\mathrm{BMC}$, research is always in progress.

Learn more biomedcentral.com/submissions 